\title{
Aprender a partir de la lectura en voz alta del adulto ${ }^{1}$
}

\begin{abstract}
Resumen: En este artículo tenemos como objetivo reflexionar sobre la lectura en voz alta del adulto dirigida a los niños pequeños. Entendemos la lectura del adulto también como una lectura del niño en un sentido vicario y metafórico. El sentido vicario viene por el hecho de que el niño participa en la lectura a través del otro que lee, al escuchar, señalar, mirar, nombrar, preguntar y comentar lo leído. Y el sentido metafórico se deriva de un "como si": como si leyera las lecturas que comparte, cuando participa en ellas. La lectura que realiza el adulto (padres o profesor/a) es una actividad en interacción con el niño antes de que sea lector autónomo. Es una forma de preparar el aprendizaje infantil de la lectura, la escritura y de promover el desarrollo del lenguaje. De la lectura en voz alta vamos a justificar su importancia y a describir algunos de sus aspectos componentes. Además, vamos a reflexionar sobre los objetivos de la lectura para los niños, sobre la selección de los libros y las maneras de leer. Finalmente, haremos una sugerencia sobre la preparación visual del texto.
\end{abstract}

Palabras Clave: Lectura en voz alta. Relación entre lengua, lectura y escritura. Libros infantiles.

\section{El aprendizaje de la lengua}

Los niños aprenden a hablar a partir de la lengua que escuchan, es decir, a partir de las palabras, expresiones y formas de comunicación que escuchan decir a los adultos que los crían, y particularmente aquellas formas que se utilizan para dirigirse directamente a ellos. En este sentido, los adultos forman parte del proceso humano de aprendizaje del lenguaje (TEBEROSKY y JARQUE, 2014). Mediante la lengua que usa, el adulto se constituye en modelo que los niños imitan; pero los niños no aprenden sólo escuchando, necesitan participar en situaciones comunicativas y tener también oportunidades frecuentes de usar (producir) esa lengua. Posiciones actuales sobre el aprendizaje del lenguaje explican que las estructuras (sonoras, lexicales, de combinación de palabras, de formulación de discursos) emergen a partir de su uso (TOMASELLO, 2003). El diálogo es el contexto principal en el que ocurre el aprendizaje del lenguaje. La investigación sobre el tipo de interacciones lingüísticas entre adultos y niños pequeños muestran que, en este contexto, tanto la calidad como la cantidad de intercambios lingüísticos son importantes para el aprendizaje. Estos argumentos están relacionados con el papel
Ana Teberosky

Universidad de Barcelona ateberosky@ub.edu

Angélica Sepúlveda Laboratório de educação (Ong), São Paulo/Brasil angelica@labedu.org.br

(1) Os editores optaram por manter a estrutura e normas das referências de acordo com o país de origen do texto. 
(2) En este artículo, usamos el término "lenguaje", en el sentido de la facultad humana de comunicarse, "lengua", como el conjunto sistematizado de palabras y construcciones de una comunidad, "habla" y "escritura" como modalidades de uso que los hablantes hacen de su lengua, "oralidad" al uso oral, "lengua escrita" a la modalidad escrita "discurso" el uso extendido de la lengua y "texto" a dicho uso en lo escrito. del input y las informaciones lingüísticas disponibles para los niños pequeños (DICKINSON, GRIFFITH, GOLINKOFF y HIRSHPASEK, 2012; KÜMMERLING-MEIBAUER y MEIBAUER, 2013) y están relacionados también con el aprendizaje cultural, en general (TOMASELLO, 2016). ${ }^{2}$

Dentro de este enfoque de aprendizaje del lenguaje, los estudios muestran que los niños pequeños extraen, almacenan y procesan construcciones basadas en el léxico de la lengua del ambiente y usan estas construcciones para estructurar sus representaciones lingüísticas (CAMERON-FAULKNER y HICKEY, 2011; D. BROWSKA y LIEVEN, 2005; THEAKSTON, LIEVEN, PINE y ROWLAND, 2002; TOMASELLO, 2003). Pero, para saber qué extraen y procesan los niños hay que analizar el discurso adulto dirigido a ellos: en esos análisis se han destacado sus características de entonación exagerada, diversidad léxica restringida, estructura simple de oraciones y enunciados relacionados con el "aquí y ahora" de la situación de enunciación (SNOW y FERGUSON, 1977).

En cuanto al aspecto cultural del proceso de aprendizaje, Tomasello, Kruger y Ratner (1993) proponen que no se trata solo de aprendizaje social, caracterizado por aprender cosas por o de otros individuos, sino de aprendizaje cultural, propio de los seres humanos, que consiste en aprender cosas a través de otros individuos. En este aprender cultural uno del otro, Tomasello (2016) incluye el aprendizaje imitativo (aprender a hacer lo que hace el otro), el aprendizaje instructivo (aprender lo que el otro me quiere enseñar) y el aprendizaje colaborativo (aprender a partir de compartir y de tomar diferentes perspectivas). En particular, el aprendizaje instructivo es el que caracteriza la situación de lectura en voz alta, que se diferencia del hablar simplemente. Según Tomasello (2016) la contribución del aprendizaje instructivo consiste en que cuando están instruyendo, los adultos transmiten información genérica, no episódica. Por ejemplo, en situación cotidiana cuando se ha caído una castaña al suelo, el adulto dice "me das esa castaña"; en situación de instrucción el adulto explica, informa, describe que las castañas son frutos de los árboles que se 1laman "castaños", que crecen en determinadas zonas templadas, etc. Es decir, comunican informaciones de tipo genérico en contextos de instrucción, el tipo de información que se encuentra en los libros. 


\section{La importancia de la lectura en voz alta para el desarrollo de la lengua y la alfabetización emergente}

Por lo general, la lectura de libros compartidos entre adulto y niños es una actividad que se estudia en la investigación educativa sobre aprendizajes escolares, específicamente en los trabajos sobre alfabetización. Sin embargo, más allá y con anterioridad a los aprendizajes escolares, en los últimos años se ha argumentado que la lectura en voz alta no solo ayuda a los niños en los procesos escolares, sino también al desarrollo general de la lengua. Las evidencias empíricas que sostienen esta afirmación vienen de numerosos estudios sobre la influencia de la lectura del adulto sobre distintos aspectos del desarrollo.

Por ejemplo, en un estudio que compara el corpus de discurso oral cotidiano dirigido a los niños (CAMERON-FAULKNER, LIEVEN y TOMASELLO, 2003) con otro corpus de lectura de 20 libros ilustrados, en términos de construcciones sintácticas y de léxico (CAMERON-FAULKNER y NOBLE, 2013). Son dos estudios que comparten la misma perspectiva de investigación sobre el aprendizaje de la lengua. En el caso de la lengua cotidiana, se presentan evidencias empíricas en el idioma inglés de que los padres usan expresiones con "marcos basados en ítems", es decir, usan frases cuya estructura sintáctica está marcada por el orden entre las palabras o por la morfología de las palabras que indican roles de los participantes en escenas (TOMASELLO, 2003, p. 139). Por ejemplo, usan marcos del tipo: "mira, es un X" (como "mira, es un gato", "mira, es el papá el que llama"). O bien construcciones con preguntas con qué, quién, dónde ("¿quién ha 1legado?", "¿qué tiene el gato?", “¿dónde está el gato?"). También marcos con "más + nombre" (del tipo “¿más agua?”, “¿más leche?”), así como construcciones con imperativos (como “¡no corras!”, "dame eso que yo lo 1levo!"). O construcciones imperativas con verbos modales (como “¡no puedes tocar eso!”). Y construcciones con verbos léxicos de alta frecuencia, ("come lo que te doy", "a ver, vamos a dibujar un muñeco" o bien "vamos a ir al super").

En el análisis de ese corpus oral cotidiano, Cameron-Faulkner et al. (2003) identificaron que más de la mitad del input de la muestra consistían en marcos basados en ítems. Stoll, Abbot-Smith y Lieven (2009) presentan resultados semejantes con un alto grado de especificidad léxica, también en otros idiomas como alemán y 
ruso, además de inglés. Los resultados de los estudios de Cameron-Faulkner et al. (2003) y Stoll et al. (2009) destacan que el número de construcciones de tipo canónicas completas, con sujeto-predicado con un verbo léxico (a diferencia de un verbo cópula, por ejemplo) es relativamente bajo. Estos autores vieron que: (i) en general, solo alrededor del 15\% de todas las expresiones tenían la forma de Sujeto-Verbo-Objeto (la mayoría de las expresiones maternas eran preguntas, imperativos, cópulas y fragmentos); (ii) el 51\% de todas las expresiones maternas comenzaron con una frase basada en ítems, la mayoría con dos palabras y (iii) después de la fase de producciones de tipo holofrase o de la combinación de dos palabras, los niños usaron muchas de estas mismas frases basadas en ítems, en correlación con la frecuencia de uso de su propia madre (CAMERON-FAULKNER et al., 2003).

Ahora bien, más allá de la lengua cotidiana de las expresiones maternas, los autores sugieren que se pueden identificar otras fuentes potenciales de aportes lingüísticos disponibles para los niños pequeños. Estos estudios señalan la lectura compartida de libros entre un adulto y los niños como otra fuente del desarrollo de la lengua, especialmente en cuanto al léxico, las construcciones gramaticales complejas y las estructuras narrativas (CAMERONFAULKNER y NOBLE, 2013). Los resultados de la comparación entre los dos estudios de Cameron-Faulkner et al. (2003) y CameronFaulkner y Noble, (2013) demuestran la prevalencia de enunciados canónicos (con orden de sujeto-verbo-objeto) y construcciones complejas en la lectura de los libros, construcciones que ocurren con muy baja frecuencia en el discurso cotidiano del adulto en interacción con el niño.

Este contenido lingüístico de los libros para niños pequeños tiene un valor potencial que puede desempeñar un papel importante en su desarrollo gramatical. La mayor frecuencia de tipos de construcción canónica y compleja ofrece dos beneficios. En primer lugar, según Cameron-Faulkner y Noble (2013), la exposición a los libros facilita la extracción, el almacenamiento y el uso posterior de las construcciones en cuestión. Por ejemplo, la mayor frecuencia de construcciones complejas proporciona a los niños pequeños información relacionada con el ordenamiento de múltiples cláusulas dentro de su lengua. En segundo lugar, los niveles más altos de exposición a construcciones canónicas pueden contribuir al conocimiento subyacente de su lengua. 
Estas construcciones canónicas con sujeto, verbo y objeto tienen el potencial de proporcionar al niño información importante relacionada con la comprensión lingüística de "quién hace qué a quién" dentro de su lengua. Por lo tanto, estos resultados sugieren que la lectura de libros compartidos puede ser un factor contribuyente en el desarrollo de construcciones complejas para niños a los que se les lee con frecuencia. Por otra parte, hay libros para la infancia que explícitamente consideran este tipo de construcciones (ver Tabla 1).

Tabla 1. Ejemplos de libros infantiles que destacan aspectos de la lengua

\begin{tabular}{|c|c|c|}
\hline ASPECTOS & $\begin{array}{l}\text { LENGUAJE Y } \\
\text { COGNICIÓN }\end{array}$ & EJEMPLOS DE LIBROS \\
\hline \multirow[t]{3}{*}{ Cortesía } & $\begin{array}{l}\text { Lenguaje figurado y } \\
\text { lenguaje formulario }\end{array}$ & $\begin{array}{l}\text { Bestiolari de la Clara de M. Desclot. } \\
\text { Bonjour et merci. Les mots magiques } \\
\text { pour être poli, de Caroline Pellissier; } \\
\text { Des mots magiques! de André Rey. }\end{array}$ \\
\hline & $\begin{array}{l}\text { Interjecciones y para } \\
\text { hacer anticipaciones }\end{array}$ & Bon dia, pollet de Mirra Ginsburg. \\
\hline & Sobre juego del intruso & Un, dos tres, qué ves? de Nadia Budde. \\
\hline Relatos con diálogos & $\begin{array}{l}\text { Construcciones } \\
\text { sintácticas: } \\
\text { a) Discurso directo }\end{array}$ & $\begin{array}{l}\text { Bon appétit, M. Lapin, de Claude } \\
\text { Boujon. }\end{array}$ \\
\hline Recetas de cocina & b) Privilegia el infinitivo & Textos con recetas de cocina \\
\hline $\begin{array}{c}\text { Relatos de sueños, } \\
\text { deseos }\end{array}$ & $\begin{array}{c}\text { c) Privilegia uso } \\
\text { subjuntivo, condicional }\end{array}$ & $\begin{array}{l}\text { ¿Qué prefieres? de John Burningham } \\
\text { (Formas con “si yo fuera...”). }\end{array}$ \\
\hline $\begin{array}{l}\text { Relatos sobre } \\
\text { algunos de los } \\
\text { argumentos del } \\
\text { verbo (¿Quién?) }\end{array}$ & $\begin{array}{l}\text { d) Privilegia el sintagma } \\
\text { nominal }\end{array}$ & Qui se cache? de P.Borsoï y M. Habert. \\
\hline $\begin{array}{l}\text { Relatos sobre } \\
\text { algunos de los } \\
\text { argumentos del } \\
\text { verbo (¿Qué?) }\end{array}$ & $\begin{array}{l}\text { e) Privilegia el } \\
\text { complemento de objeto } \\
\text { directo }\end{array}$ & $\begin{array}{l}\text { On ne peut pas, de Asbé. Pastel; Le roi } \\
\text { des bons, de Pef. Folio Benjamin; ¿Qué } \\
\text { es?, de Leo Leoni. }\end{array}$ \\
\hline $\begin{array}{c}\text { Relatos sobre } \\
\text { algunos de los } \\
\text { argumentos del } \\
\text { sintagma (¿Dónde?) }\end{array}$ & $\begin{array}{l}\text { f) Privilegia el } \\
\text { complemento de lugar }\end{array}$ & Où, précisément, de Tana Hoban. \\
\hline $\begin{array}{l}\text { Relatos sobre } \\
\text { algunos de los } \\
\text { argumentos del } \\
\text { sintagma (¿Por } \\
\text { qué?) }\end{array}$ & $\begin{array}{l}\text { g) Privilegia el } \\
\text { complemento de causa }\end{array}$ & $\begin{array}{c}\text { Il ne faut pas habiller les animaux, de } \\
\text { Barret; Cuentos por teléfono, de G. } \\
\text { Rodari. }\end{array}$ \\
\hline
\end{tabular}




\begin{tabular}{|c|c|c|}
\hline $\begin{array}{c}\text { Relatos sobre } \\
\text { algunos de los } \\
\text { argumentos del } \\
\text { sintagma (¿Cómo?) }\end{array}$ & $\begin{array}{l}\text { h) El relato organizado } \\
\text { sobre la comparación y } \\
\text { el contraste }\end{array}$ & Un, deux, trois, M. Pétunia, de Blake. \\
\hline $\begin{array}{l}\text { Diferentes puntos } \\
\text { de vista }\end{array}$ & $\begin{array}{l}\text { Comparación de puntos } \\
\text { de vista y doble punto } \\
\text { de vista }\end{array}$ & $\begin{array}{l}\text { Voces en el parque de Anthony Browne } \\
\text { (un mismo acontecimiento relatado } \\
\text { cuatro veces). } \\
\text { Rana de Maria Paula Bolaños } \\
\text { (contrapunto entre texto e ilustración). }\end{array}$ \\
\hline $\begin{array}{l}\text { Relato en primera } \\
\text { persona }\end{array}$ & $\begin{array}{l}\text { Las personas del } \\
\text { narrador }\end{array}$ & $\begin{array}{l}\text { Autobiografía de un oso de peluche: } \\
\text { Otto, de Tomi Ungerer. }\end{array}$ \\
\hline $\begin{array}{l}\text { Nombres y } \\
\text { categorías }\end{array}$ & $\begin{array}{l}\text { Relaciones semánticas } \\
\text { Hiperonímia } \\
\text { Antonimia }\end{array}$ & $\begin{array}{c}\text { Sofía, la vaca que amaba la música de } \\
\text { Geoffroy de Pennart. } \\
\text { Cuentos de contrarios }\end{array}$ \\
\hline Definiciones & $\begin{array}{l}\text { Definiciones y } \\
\text { sentimientos }\end{array}$ & Mania de explicação de Adriana Falcão. \\
\hline Relatos, juegos, etc. & Morfología & $\begin{array}{l}\text { El país con el "des" delante de G. } \\
\text { Rodari Cuentos por teléfono. } \\
\text { Não confunda de Eva Furnari. }\end{array}$ \\
\hline Abecedarios & Aspectos de lo escrito & Abecedarios \\
\hline \multirow[t]{2}{*}{ Cuentos } & Ortografía & $\begin{array}{c}\text { Proceso de Gianni Rodari, Cuentos por } \\
\text { teléfono. }\end{array}$ \\
\hline & Resolución de problemas & $\begin{array}{l}\text { El ogro, el lobo, la niña y el pastel } \\
\text { de Philippe Corentin; iCataplum! de } \\
\text { Philippe Corentin; Il était une fois, de A. } \\
\text { Serres; Una noche, un gato... de Yvan } \\
\text { Pommaux. }\end{array}$ \\
\hline
\end{tabular}

Fuente: elaboración propia.

Respecto a las etapas escolares posteriores, creemos que la lectura en voz alta aporta muchos conocimientos a los escolares: aportan formas de pronunciación y prosodia, así como énfasis y comentarios, y continúan los aprendizajes compartidos. Las investigaciones encuentran un efecto positivo de la lectura en voz alta sobre muchos de los aprendizajes que se desarrollan en la escuela, por ejemplo, sobre los enunciados con estructura de preguntas abiertas (BLEWITT, RUMP, SHEALY y COOK, 2009), sobre el desarrollo del vocabulario (SÉNÉCHAL Y LEFEVRE, 2002), sobre los diálogos porque mejoran y amplían las habilidades conversacionales (MORROW, 1988), sobre la comprensión (BUS, VAN IJZENDOORN y PELLEGRINI, 1995), sobre el desarrollo 
narrativo (REESE, 1995), sobre las capacidades pragmáticas, como entender que las preguntas son pistas para comenzar un proceso de comunicación y, fundamentalmente sobre la alfabetización emergente (TEALE y SULZBY, 1986). Además, varios estudiosos indican que los libros de imágenes contribuyen decisivamente a la adquisición de habilidades metalingüísticas y meta-literarias (KÜMMERLING-MEIBAUER y MEIBAUER, 2013).

\section{Duración de la lectura en voz alta ¿hasta cuándo leer en voz alta a los niños?}

Es frecuente que la lectura en voz alta del adulto se relacione con los niños pequeños, pues cuando los niños comienzan a ser lectores autónomos los adultos (padres y profesores) dejan de leerles. Middleton (2005) sostiene que nuestra idea de leer un libro está relacionada con una práctica solitaria, individual y autónoma de un lector silencioso. Se trata la lectura como una actividad cognitiva que tiene lugar en un ámbito mental, como los sueños, los pensamientos o los recuerdos. Sin embargo, puede haber un desempeño oral de los textos, con verbalizaciones, porque la lectura silenciosa es solo un tipo de lectura. La lectura con voz, la actuación oral de un texto, sigue siendo importante durante toda la escolaridad.

¿Qué aporta la lectura en voz alta? Middleton (2005) la compara con una obra de teatro, donde la audiencia participa y entra imaginativamente en los espacios ficticios y narrativos de la puesta en escena. Aunque las audiencias de la lectura tienen condiciones diferentes (las luces no se atenúan, la audiencia es consciente de su co-presencia, las personas se conocen entre sí) tienen algo en común con las audiencias del teatro, con la expresión compartida de emociones como la risa, el shock o la tristeza.

Esta posición está en consonancia con diversos estudios que fueron diseñados para investigar el papel de las actuaciones del adulto durante la lectura, por ejemplo, específicamente en el caso de los gestos, algunos estudios muestran su papel en la comprensión narrativa de los niños (PARIS y PARIS, 2003; MAR, 2004; MACOUN y SWELLER, 2016).

Por otra parte, también coincide con la historia de la lectura que muestra que la manera de leer en voz alta de forma expresiva y actuada ha dejado huellas en la representación gráfica de los textos, huellas en marcas gráficas y tipográficas (MORRISON, 1995). 
Los libros actuales presentan esas marcas que orientan al adulto en los aspectos prosódicos de la lectura: cómo indicar el comienzo de la narración, cómo diferenciar entre narración y diálogos, con qué énfasis indicar las citas, el título, los aspectos del contenido, etc. Las indicaciones evidentemente influyen no solo en la forma de oralizar el texto, sino también en el uso de la entonación, las voces y los gestos. Es posible, también, que los indicadores de actuación de la lectura oralizada, cuando coinciden con la visualización del texto, puedan servir de base para el uso de los recursos visuales en la producción de los niños (TEBEROSKY y SEPÚLVEDA, en prensa). Si el niño ha sido expuesto a "oír leer y mirar el texto" en una lectura multimodal, con una visualización de los textos y la presencia de voz, entonación, miradas, gestos, etc., seguramente habrá podido seguir cómo esa lectura coincide con formas, color, tipografía, tamaño de las grafías e incluso imágenes en movimiento y con gestos, tonos, y voces de la lectura.

\section{Los objetivos de la lectura y la selección de los libros}

El objetivo general de la lectura en voz alta es el aprendizaje, incluso aunque los niños no sean lectores autónomos. Desde el comienzo, el fin de la lectura es aprender: aprender cosas sobre el mundo, aprender lengua, a leer y a escribir. Es decir, aprender vocabulario, estructuras gramaticales, o formas discursivas de los textos. Se aprende a entender cuál es la trama de las narraciones, a entender la ficción y el lenguaje figurado, así como se aprende a entender otras mentes, otras emociones y experiencias (NIKOLAJEVA, 2012a, 2012b, 2013). También se puede leer para estudiar nuevos conceptos, y si se leen varios textos, se aprenden aspectos metatextuales. Al leer se aprende a hablar de forma más próxima a los libros y a escribir; es decir, se aprende la relación entre lengua, leer y escribir.

Pero, tal como se representa en las secciones de las librerías, no se lee para aprender de la misma manera a edades diferentes. Los objetivos de la lectura están en interacción con las edades y los niveles de desarrollo. Por ejemplo, considerando las edades correspondientes a pre-escolar y primaria:(i) para los más pequeños se seleccionan libros sobre aspectos descriptivos de dominios conceptuales básicos, porque sirven para aprender vocabulario; libros con tramas repetitivas porque permiten entender la estructura de los eventos y anticipar los componentes 
temporales de la narración; libros con diálogos porque ayudan a la repetición o citación de las palabras de los personajes, y libros con juegos de lenguaje para estimular la conciencia metalingüística. Posteriormente, (ii) para los niños durante la educación primaria, son útiles los libros sobre aspectos descriptivos de dominios específicos (temas sobre la historia de personajes, sobre la vida de los animales, etc.), libros de tramas con características enigmáticas porque desencadenan la expresión y/o con un final inesperado o final abierto para estimular la conjetura y favorecer la relectura, o libros de temas sobre aspectos psicológicos, como cuentos con mentiras o cuentos con moraleja.

La selección de los libros debería estar guiada por la perspectiva de que la lectura facilita el conocimiento de la relación entre lengua, leer y escribir a las diferentes edades. El destinatario de estas lecturas es un niño, hablante de la lengua de su comunidad, de una lengua oral con mayor o menor influencia del lenguaje escrito. Por ello, la selección de los libros cobra mayor importancia. Para realizar esta selección cabrá preguntarse ¿cuáles libros ayudan en esta relación? Para hacer la elección se deberá tener en cuenta la edad de los aprendices con el objetivo de desencadenar su actividad lingüística y cognitiva, a fin de que se aliente su participación. Respecto a la edad, una de las características más importantes de los libros de literatura infantil es la asimetría entre el nivel cognitivo del emisor (adulto, lector o escritor) y el destinatario implícito (el niño) (KÜMMERLINGMEIBAUER y MEIBAUER, 2013).

Nikolajeva (2003) sostiene que muchas veces la elección se basa en opiniones de los adultos no bien fundamentadas, como la opinión de que tienen que tener una trama simple, claramente delimitada, sin digresiones, siguiendo el orden cronológico de los eventos, con un número limitado de personajes fáciles de recordar, con un contenido temático adecuado para fines didácticos o morales. Sin embargo, la cuestión de la edad es decisiva en la elección, no por las anteriores razones, sino porque los distintos niveles del desarrollo de la lengua condicionan la comprensión del texto y también a la inversa, porque el texto que se lee al niño es un input específico para dicho desarrollo. Esta interacción nos indica que en la selección de libros debe considerarse una descripción de sus características, así como una descripción del desarrollo cognitivo del niño, del cual el desarrollo del lenguaje forma parte. 
Por ejemplo, para las edades tempranas, la relación entre lengua, lectura y escritura se hace presente a través de las características de la oralidad. Estas características pueden reconocerse no solo en la prosodia del lector al dramatizar la lectura, sino también en índices verbales, como los juegos sonoros de puro deleite acústico, en la repetición de cadenas de tipo acumulativa, que están presentes en los juegos verbales infantiles:

Estaba la rana sentada cantando debajo del agua cuando la rana salió a cantar vino la mosca y la hizo callar la mosca a la rana que estaba cantando debajo del agua cuando la mosca salió a cantar vino la araña y la hizo callar

Además de estas características de oralidad, los libros para los más pequeños presentan dominios conceptuales sobre la base de descripción a través de imágenes y textos, es decir, aquellos libros de imágenes que no contienen ninguna historia, pero muestran imágenes de objetos cotidianos, como juguetes, animales y automóviles, lo que supone una ayuda al aprendizaje lexical y a la categorización conceptual.

Así también hay libros con variaciones en el relato, como el final trunco o un final abierto y, como en el caso de Sherezade de Las mil y una noches, que es el prototipo de uso de esta técnica, sirven para mantener la atención del auditorio. En fin, varios libros tienen explícitamente el objetivo del desarrollo del conocimiento de la relación entre lengua, leer y escribir. Hemos hecho una pequeña lista que muestra que, en varias lenguas (castellano, francés, portugués, inglés), los autores y editores promueven este tipo de libros (ver Tabla 1).

\section{Las maneras de leer}

La actividad de lectura en voz alta se puede realizar de muchas maneras: de hecho, a lo largo de la historia de la humanidad se ha realizado de diversas formas. Por ejemplo, Margit Frenk (2015, p. 1139) nos explica las maneras frecuentes en el Siglo de Oro Español, cuando la mayoría de la población no sabía leer, pero en todas partes y niveles sociales había algunos que sí leían y que 
solían leer en voz alta para un grupo de oyentes. Se trataba de un espectáculo de lectura oral conjunta, más que individual, en el que se usaba la forma plural leamos, como relata Cervantes en el Quijote, donde uno leía y el resto escuchaba (FRENK, 2015, p. 1140). Frenk refiere la ausencia de especificidad de las actividades relacionadas con lo escrito: el verbo leer podía usarse como sinónimo de oír lo que otro leía en voz alta; y el verbo decir compartía significado con recitar, relatar, contar, narrar, referir de memoria. Por supuesto, leer también podía significar leer en silencio, además de en voz alta para sí mismo, para memorizar el texto.

Cuando Frenk habla de "espectáculo" (las comillas son 1a autora, p. 1139) se refiere al arte de recitar, a la técnica narrativa del decir de los juglares que usaban las inflexiones de la voz, la actuación, la teatralización en la presentación de los personajes, las interpelaciones al lector (oyente) y hasta la digresión del texto. Es decir, toda una serie de técnicas de la oralidad ausentes en la lectura silenciosa. Otro crítico literario de la obra del Siglo de Oro, M. Moner (1997), denomina "arte verbal" a la oralidad dedicada no a lectores sino a oyentes, propia de la época.

En el contexto de la lectura en voz alta dirigida a los niños queremos llamar la atención sobre la semejanza con algunas de estas técnicas. Evidentemente, no se trata de una real representación teatral, como muchas veces ha sugerido la didáctica, sino de la adaptación de ciertos aspectos multimodales propios de la comunicación oral a la situación de lectura dirigida a un niño del que sabemos que no comparte nuestra capacidad de leer o los conocimientos sobre lo leído.

La influencia de la lectura dirigida a niños reside no solo en la oralización del texto, sino también en las actuaciones del adulto que suele acompañar dicha lectura con recursos de expresión facial, miradas, uso de gestos, orientación corporal, etc. Estas actuaciones sirven para indicar a los niños varios aspectos del texto, como la presentación de los personajes, los contextos, los diálogos, las enumeraciones, la repetición, la información redundante, entre otros. Por otra parte, responden a la forma en que se dirigen los adultos a los niños, tanto en la conversación (por ejemplo, en el lenguaje dirigido a los bebés, KARMILOFF y KARMILOFF-SMITH, 2005; PAN y SNOW, 1999; TOMASELLO, 2003), como en la lectura en voz alta. 
El uso de gestos durante la lectura forma parte del uso más general durante el habla: los hablantes usamos gestos de formas diversas y con diferentes funciones durante la comunicación. Algunos son gestos convencionales y pueden reemplazar discurso (que se denominan emblemas, como en la cultura occidental el gesto con los dedos en forma de $\mathrm{V}$ o el gesto de OK). Otros son gestos espontáneos que acompañan el discurso y muestran variación entre los hablantes, son menos convencionalizados y están relacionados con el significado del segmento lingüístico al que acompañan (se denominan 'gesticulación', según OZYÜREK, 2011).

Los que estudian los gestos de comunicación suelen clasificarlos en los siguientes términos, según Ozyürek (2002):

Icónicos, describen referentes concretos o acciones del discurso en función de su semejanza. Por ejemplo, representar "libro" con un gesto mimético de abrir y cerrar las dos manos como si se tuviera el objeto, o la dirección indicando la trayectoria de las figuras en movimiento.

Metafóricos, representan imágenes o referentes abstractos, transmiten información y representan conceptos sin forma física. Por ejemplo, el enunciado "la historia sigue y sigue", se acompaña de las manos del orador imitando un movimiento giratorio.

Golpes, también llamados de batuta, representan movimientos rítmicos con la mano o los dedos que acompañan el habla, describen enumeraciones o el ritmo del discurso,

Deícticos representan puntos señalados para la localización de entidades o personajes en el espacio, de objetos o personas. Por ejemplo, gestos de señalamiento indicando el lugar dónde se encuentran.

Una de las cuestiones interesantes respecto al uso de gestos está en la relación con la lengua. Ozyürek (2002, 2011) sostiene que puesto que gesto y lengua interactúan se espera que esas interacciones ocurran no sólo durante la producción sino también durante la comprensión. Durante la producción, el acto de gesticular tiene una función interna para el productor. Según refieren los estudios mencionados, la función interna puede consistir en facilitar el acceso al léxico, reducir la carga cognitiva o proporcionar una simulación de acciones para el hablante 
(GOLDIN-MEADOW, NUSBAUM, KELLY y WAGNER, 2001; PING y GOLDIN-MEADOW, 2010; MACOUN y SWELLER, 2016).

La segunda función consiste en que el gesto sirve a la comunicación externa y se produce principalmente para ayudar a la comprensión del receptor (ÖZYÜREK, 2002). Por tanto, tiene una motivación comunicativa y social. Puesto que los hablantes saben de la atención que prestan los oyentes, no solo a la información del habla sino también al gesto, usan ambos para comunicar. Debido a este valor comunicativo, la investigación sobre narración y lectura en voz alta sugiere usar estas diferentes formas de apoyo de la oralidad, con voz y prosodia, así como con gestos (icónico, deíctico y golpes), para ayudar a la comprensión y memoria de los textos en la enseñanza.

\section{La preparación visual del texto para la lectura en voz alta}

Durante mucho tiempo, el texto para la lectura en voz alta se preparaba en una disposición especial, denominada per cola et commata, es decir, con puntuación dividiendo las líneas del texto por cláusula y frase. Esta disposición se conoce desde el siglo IV: fue San Jerónimo quien descubrió ese recurso y lo usó en su traducción al latín del Libro de Ezequiel, para beneficio de los lectores, "lo que está escrito per cola et commata resulta más fácil de entender para los lectores" (MANGUEL, 2001, p. 78). Las unidades pueden consistir en frases nominales, aposiciones, frases adjetivas, preposicionales, cláusulas subordinadas, o elementos de una lista, entre otros. El editor elige entre dividir las líneas en unidades más pequeñas o bien combinarlas en unidades mayores (HARRISON, 2007).

Esta disposición del texto no solo ayuda en la oralización de la lectura con voz, sino que también ayuda a la comprensión. Ayuda en el sentido analítico, porque con la disposición y la puntuación se hacen más accesibles visualmente los componentes de la lengua (léxico y sintaxis), así como en el sentido sintético al "poner junto" (etimológicamente com-prender) lo que necesita ser conectado (CÈBE, GOIGOUX y THOMAZET, 2004).

El uso de la estructura del texto está también demostrado en las investigaciones sobre comprensión (MEYER, BRANDT y BLUTH, 1980; MEYER y RAY, 2011). Los lectores que usan una "estrategia de estructura" buscan identificar y usar la organización del texto para su propia comprensión. La estrategia de estructura 
facilita la comprensión al ayudar al lector a organizar conceptos, identificando y visualizando las relaciones explícitas o implícitas que son comunicadas por el texto. Las conexiones causales y temporales se centran en las relaciones de causa-efecto y orden que conforman la estructura lógica del texto narrativo, al igual que las estructuras lógicas se complementan para establecer la estructura del texto de no ficción. Las estructuras no solo describen el texto en sí, sino que también caracterizan la coherencia cognitiva de las representaciones de los lectores.

\section{Conclusiones}

La lectura en voz alta del adulto dirigida a los niños puede crear importantes oportunidades de desarrollo y aprendizaje de la lengua, la lectura y la escritura. Se trata de un modo privilegiado de enriquecer la lengua al que se expone a los niños, pues a diferencia de la interacción conversacional de la vida cotidiana, el lenguaje de los libros contiene diversidad de ejemplares de formas y usos de la lengua para expresar significados. Sin embargo, estos aprendizajes dependen de la calidad y frecuencia de los eventos de lectura. En cuanto a la calidad, hemos considerado aspectos relacionados con la oralización de los textos y aspectos relacionados con la selección de los libros. La frecuencia también influye en el desarrollo de la lengua, tal como se ha mostrado en la alfabetización emergente a partir del uso en interacción con los adultos.

Así, destacamos modos de leer expresivos y responsivos, con visualización de los textos, que favorezcan intencionadamente la comprensión y la participación de los niños. Y, en cuanto a la selección de los libros, propusimos considerar aspectos evolutivos y en el caso de los niños preescolares optar por libros sobre aspectos descriptivos de dominios conceptuales básicos (de vocabulario, por ejemplo), libros con estructuras recurrentes, con final trunco, juegos de lengua y diálogos; y para los niños durante la educación primaria, optar por libros sobre aspectos descriptivos de dominios específicos/ enciclopédicos, libros de historias con engaño, con moraleja, con personajes que exhiben aspectos emocionales, libros que exigen considerar varios puntos de vista, con aspectos enigmáticos, con final inesperado o abierto. En resumen, libros que puedan ser leídos, comentados e interpretados de forma recurrente 
y que estimulen diferentes tipos de respuestas y producciones orales y escritas por parte los niños.

\title{
Learning from adult's reading aloud
}

\begin{abstract}
The aim of this paper is to reflect on the reading aloud of the adult addressed to the child. We understand by reading aloud the activity of the adult directed to the child, which is also a reading of the child in a vicarious and metaphorical sense. It is a vicarious because the child participates in reading through another who reads, when he hears, points, looks, names, asks and comments on what the adult has read. And the metaphorical sense derives from a "as if": as if the child read the readings he shares with the adult; when he participates in them. The adult (parents or teacher) performs their readings in interaction with the child before he is an autonomous reader. It is a way to prepare children's learning of reading, writing and to promote the development of language. We are going to justify reading aloud and describe some of its components. In addition, we will reflect on the objectives of reading for children, on the selection of books and ways of reading. Finally, we will make a suggestion about the visual preparation of the text.
\end{abstract}

Keywords: Reading aloud. Relationship between language, reading and writing. Children's books.

\section{Aprender a partir da leitura em voz alta do adulto}

Resumo: Neste artigo temos o objetivo de refletir sobre a leitura em voz alta do adulto dirigida às crianças pequenas. Entendemos a leitura do adulto também como uma leitura da criança em um sentido vicário e metafórico. O sentido vicário porque a criança participa da leitura através de outro que 1ê, quando ouve, assinala, observa, nomeia, pergunta e comenta o lido. E o sentido metafórico se deriva de um "como se": como se a criança lesse as leituras que comparte com o adulto quando participa delas. A leitura que realiza o adulto (pais ou professor/a) é uma atividade de interação com a criança antes de que esta seja uma leitora autônoma. É uma forma de preparar a aprendizagem infantil da leitura e da escrita e de promover o desenvolvimento da linguagem. Da leitura em voz alta vamos a justificar sua importância e descrever algumas de suas características. Além disso, vamos refletir sobre os objetivos da leitura para crianças, a seleção dos livros e as maneiras de ler. Finalmente, faremos sugestões sobre a preparação visual do texto.

Palavras-chave: Leitura em voz alta. Relação entre língua, leitura e escrita. Livros infantis.

\section{Referencias}

BLEWITT, Pamela; RUMP, Keiran; SHEALY, Stephanie; COOK, Samantha. Shared book reading: when and how questions affect young children's word learning. Journal of Educational Psychology, 101, 294-304, 2009 .

BUS, Adriana; VAN IJZENDOORN, Marinus; PELLEGRINI, Antohny. Joint book reading makes for success in learning to read: A meta- 
analysis on intergenerational transmission of literacy. Review of Educational Research, 65, 1-21, 1995.

CAMERON-FAULKNER, Thea; LIEVEN, Elena; TOMASELLO, Michael. A Construction based analysis of child directed speech. Cognitive Science, 27, 843-873, 2003.

CAMERON-FAULKNER, Thea; HICKEY, Tina. Form and function in Irish child directed speech. Cognitive Linguistics, 22, 3, 569-594, 2011.

CAMERON-FAULKNER, Thea; NOBLE, Claire. A comparison of book text and Child Directed Speech. First Language, 33: 268-279, 2013.

CÈBE, Sylvie; GOIGOUX, Roland; THOMAZET, Serge. Enseigner la compréhension. Principes didactiques, exemples de tâches et d'activités. Lire écrire, un plaisir retrouvé, MEN-DESCO, 2004.

DABROWSKA, Ewa; LIEVEN, Elena. Towards a lexically specific grammar of children's question constructions. Cognitive Linguistics, 16, 3, 437-474, 2005.

DICKINSON, David; GRIFFITH, Julie; GOLINKOFF, Roberta; HIRSHPASEK, Kathy. How reading books fosters language development around the world. Child Development Research, ID 602807, 1-15, 2012.

FINNEGAN, Ruth. The how of literature. Oral Tradition, 20/2, 164-187, 2005.

FRENK, Margit. Oralidad, lectura, escritura. In: Real Academia Española y Asociaciones de Academias de la Lengua Española. Miguel de Cervantes, Don Quijote de la Mancha (pp. 1138-1144). Madrid: Real Academia Española y Asociaciones de Academias de la Lengua Española, 2015.

GOLDIN-MEADOW, Susan; NUSBAUM, Howard; KELLY, Spencer; WAGNER, Susan. Explaining math: gesturing lightens the load. Psychological Science, 12, 6, 516-522, 2001.

HARRISON, Rebecca. A structural arrangement of text to facilitate reading. Classical Journal 102.3, 291-303, 2007.

HUTTENLOCHER, Janellen; VASILYEVA, Marina; CYMERMAN, Elina; LEVINE, Susan. Language input and child syntax. Cognitive Psychology, 45, 337-374, 2002.

KÜMMERLING-MEIBAUER, Bettina; MEIBAUER, Jörg. Maps in picture books: cognitive status and narrative functions. Nordic Journal of ChildLit Aesthetics, 6, 1-10, 2015.

MACOUN, Alice ; SWELLER, Naomi. Development listening and watching: The effects of observing gesture on preschoolers' narrative comprehension. Cognitive Development, 40, 68-81, 2016.

MANGUEL, Alberto. Una historia de la lectura. Madrid: Alianza Editorial, 2001, versión original, 1996. 
MEYER, Bonnie; RAY, Melissa. Structure strategy interventions: in creasing Reading comprehension of expository text. International Electronic Journal of Elementary Education, 4, 1, 127-152, 2011.

MIDDLETON, Peter. How to read a reading of a written poem. Oral tradition, 20,1, 7-34, 2005.

MONER, Michel. Técnicas del arte verbal y oralidad residual en los textos cervantinos. In: J. Montero Requena (Recopilación). Antología de la crítica sobre El Quijote en el siglo XX. Madrid: Centro Virtual Cervantes, 1997.

MORRISON, Ken. Fijación del texto: la institucionalización del conocimiento en formas históricas y filosóficas de la argumentación ( $p$. 133-187). In: J. Bottero (Ed.). Cultura, pensamiento escritura. Barcelona: Gedisa, 1995, original, 1987.

MORROW, Lesley. Young children's responses toone-to-one story readings in school settings. Reading Research Quarterly, 23, 89-107, 1988.

NINIO, Anne; BRUNER, Jerome. The achievement and antecedents of labeling. Journal of Child Language, 5, 1-15, 1978.

NIKOLAJEVA, Maria. Verbal and visual literacy: the role of picture books in the reading experience of young children. In: N. Hall, J. Larson \& J. Marsh (Eds.). Early Childhood Literacy (235-248). London: Sage Publications, 2003.

NIKOLAJEVA, Maria. Literacy, competence and meaning-making: a human sciences approach. Cambridge Journal of Education, 40, 2, 145-159, 2011.

NIKOLAJEVA, Maria. Guilt, empathy and the ethical potential of children's literature. Journal of Children's Literature Research, 35, 2012a.

NIKOLAJEVA, Maria. Reading Other People's minds through word and mirage. Children's Literature in Education, 43, 273-291, 2012b.

NIKOLAJEVA, Maria. Picture books and emotional literacy. The Reading Teacher, 67, 4, 249-254,2013.

OZYÜREK, Asli. Do speakers design their co-speech gestures for their addressees? The effects of addresse elocation on representational gestures. Journal of Memory and Language, 46, 688-704, 2002.

OZYÜREK, Asli. Language in our hands: The role of the body in language, cognition and communication. Radboud Universiteit Nijmegen, 2011.

PING, Raedy; GOLDIN-MEADOW, Susan. Gesturing saves cognitive resources when talking about non-present objects. Cognitive Science, 34, 4, 602-619, 2010.

REESE, Elaine. Predicting children's literacy from mother-child conversations. Cognitive Development, 10, 381-405, 1995. 
SÉNÉCHAL, Monique; LEFEVRE, Jo-Anne. Parental involvement in the development of children's reading skill: A five-year longitudinal study. Child Development, 73, 445-460, 2002.

SNOW, Catherine; FERGUSON, Charles. Talking to children: Language input and acquisition. Cambridge: Cambridge University Press, 1977.

STOLL, Sabine; ABBOT-SMITH, Kirsten; LIEVEN, Elena. Lexically restricted utterances in Russian, German, and English Child-Directed Speech. Cognitive Science, 33, 75-103, 2009.

TEALE, William; SULZBY, Elizabeth. Emergent literacy as a perspective for examining children become writers and readers. In: W. Teale y E. Sulzby (Eds.). Emergent literacy: Writing and Reading (pp. VII-XXV). Norwood, NJ.: Ablex, 1986.

TEBEROSKY, Ana; JARQUE, Maria-Josep. Interacción y continuidad entre la adquisición del lenguaje y el aprendizaje de la lectura y la escritura. Ruta Maestra, 8, 21-26, 2014.

TEBEROSKY, Ana; SEPÚLVEDA, Angélica. A construção infantil das unidades do texto. In: J. Correa; A. Galvão Spinillo (Org). A escrita de textos por crianças: limites, possibilidades e implicações educacionais, no prelo.

THEAKSTON, Anna; LIEVEN, Elena; PINE, Julian; ROWLAND, Caroline. Going, going, gone: the acquisition of the verb 'go'. Journal of Child Language, 29, 783-811, 2002.

TOMASELLO, Michael. Constructing a language: A usage-based approach of language acquisition. Cambridge, MA: Harvard University Press, 2003.

TOMASELLO, Michael. Cultural Learning Redux. Child Development, 87, 3, 643-653, 2016.

TOMASELLO, Michael; KRUGER, Ann; RATNER, Hilary. Cultural learning. Behavioral and Brain Sciences, 16, 495-552, 1993.

Submetido: 10/01/2018.

Aceito: 19/04/2018. 